\title{
International Journal of

\section{Akinetic Mutism after Shunt Failure: Short Communication with a Review of the Literature}

\section{Sang Bong Chung and Myoung Soo Kim}

Department of Neurosurgery, National Medical Center, Euljiro 245, Jung-gu, Seoul, Republic of Korea

*Corresponding author: Myoung Soo Kim, MD, Department of Neurosurgery, National Medical Center, Euljiro 245, Jung-gu, Seoul, Republic of Korea, Tel: 222607180; Fax: 222624869; E-mail: hanibalkms@hanmail.net

Received date: November 15, 2017; Accepted date: November 21, 2017; Published date: November 28, 2017

Copyright: (C) 2017 Chung SB, et al. This is an open-access article distributed under the terms of the Creative Commons Attribution License, which permits unrestricted use, distribution, and reproduction in any medium, provided the original author and source are credited.

\section{Abstract}

Akinetic Mutism (AM) is an infrequent, but profound complication of recurrent obstructive hydrocephalus. This condition has a tendency not to improve, either spontaneously or with restoration of shunt function. Occasionally, complete recovery of hydrocephalic-related AM has been achieved with bromocriptine. However, we do not have detailed guidelines for dosage or duration of bromocriptine treatment. Therefore, we reviewed pharmacological treatments for AM because of shunt failure. Finally, we suggest appropriate treatment guidelines for this type of AM.

Keywords: Akinetic mutism; Bromocriptine; Pharmacological treatments

\section{Introduction}

Akinetic mutism (AM) related to recurrent shunt failure in hydrocephalic patients has been reported only rarely [1-10]. This condition has a tendency not to improve, either spontaneously or with shunt revisions. Occasionally, complete recovery of hydrocephalicrelated AM has been achieved with bromocriptine [1,2,4-10]. However if high-dose bromocriptine is used, we experienced bromocriptinerelated side effects (e.g. dyskinesia). Appropriate duration and dosage of bromocriptine therapy for this type of AM appears controversial. Empirical treatment that may require several cycles of weaning and restarting until the patient's signs and symptoms finally resolve seems required.

In Therefore, we reviewed the literature on the pathogenesis and treatment for this type of AM, especially focused on drug treatment.

\section{Pathogenesis of AM because of Recurrent Shunt Failure in Obstructive Hydrocephalus}

Most patients with AM related to recurrent shunt failure had obstructive hydrocephalus caused by aqueductal stenosis, either congenital or acquired. A review of previous cases of AM reveals that the syndrome usually develops after multiple shunt revisions because of shunt failure [1,3-8,10]. As highlighted by Anderson [5], this observation suggests that the brain undergoes a series of stretching and contraction cycles, so the repeated cycles of ventricular dilatation and relaxation in multiple shunt failure may somehow alter their physical characteristics, resulting in a more rapid dilation according to increased intracranial pressure, which exceeds the speed of compensatory mechanisms and results in damage.

A lack of communication between the ventricular cavities in obstructive hydrocephalus because of aqueductal stenosis creates a steep pressure differential between the supratentorial and infratentorial compartments. In particular, in aqueductal stenosis, most of the significant anatomical distortion of structures is developed at the level of the third ventricle. Recurrence of the hydrocephalus caused by ventriculoperitoneal shunt dysfunction alters diencephalic monoamine projections, resulting in AM [1].

In humans, four dopaminergic pathways exist. The first is the mesolimbic pathway, sometimes referred to as the reward pathway. This system projects from the ventral tegmental area to the ventral striatum. It is one of the component pathways of the medial forebrain bundle. The mesolimbic pathway regulates incentive salience, motivation, reinforcement learning and fear. Second is the mesocortical pathway connecting the ventral tegmental area to the prefrontal cortex. This pathway is thought to be involved in cognitive control, motivation and emotional response. Third is the nigrostriatal pathway connecting the substantia nigra pars compacta with the dorsal striatum (i.e., the caudate nucleus and putamen). This pathway is particularly involved in modulation of the extrapyramidal system. Fourth is the tuberoinfundibular pathway projecting from the arcuate nucleus in the tuberal region of the hypothalamus to the median eminence. This pathway regulates the secretion of prolactin from the anterior pituitary gland.

Patients with AM after shunt failure lack other features of dopamine insufficiency, such as tremor or rigidity, suggesting a restricted lesion of the dopamine pathways. The underlying mechanism of AM because of recurrent shunt failure is believed to be damage to the periventricular monoamine projections in the thalamus and hypothalamus (mesolimbic pathway and mesocortical pathway) caused by the expansion of the third ventricular wall. This is the theoretical basis for use of a dopamine agonist in humans with AM, providing effective results.

\section{Treatment of AM because of Recurrent Shunt Failure in Obstructive Hydrocephalus}

After the AM during shunt malfunction in case of obstructive hydrocephalus has been reported to resolve after neuroendoscopic third ventriculostomy with removal of the previous shunt system [11]. Third ventriculostomy is reported as an ideal solution for treatment of this type of AM because of its effect by creating communication 
between the third ventricle and the subarachnoid spaces. However, this successful treatment has only been reported once [11].

Several reports suggested that this type of AM responds well to bromocriptine, a dopaminergic agonist, but not with levodopa, because presynaptic dopaminergic mechanisms are inoperable in these cases [12]. Most reports described an excellent effect of bromocriptine $[1,2,4-6,8-10]$. However, other reports described difficulty in the withdrawal of bromocriptine [2,5,9]. In a case reported by Anderson [5], the attempt to withdraw bromocriptine induced abrupt deterioration of behavior, spontaneous movements and deterioration of alertness [5]. These symptoms disappeared after restarting bromocriptine [2,5,9]. Kim et al. [2] also reported that bromocriptine dose reduction because of dyskinesia that developed five months after initiation of bromocriptine resulted in the abrupt reappearance of AM and a return to the original dosage of bromocriptine resolved the symptoms of AM.

Some authors also reported side effects of high-dose bromocriptine (e.g. drug-induced dyskinesia) [2]. In Parkinson's disease, levodopainduced dyskinesia has been reported to develop after long-term usage of levodopa. Kim et al. [2] reported dyskinesia after just five months of bromocriptine treatment in AM after shunt operation of hydrocephalus because of aqueductal stenosis. Patients with AM because of shunt failure are generally young or middle-aged. Therefore, long-term and safe usage of bromocriptine is important in treatment. Why does dyskinesia develop despite short-term usage of bromocriptine? In our opinion, this might be related to its capacity for dopamine production. Kim et al. [2] reported that a patient with AM showed normal dopamine production. In situations of normal dopamine production, high-dose bromocriptine may result in druginduced dyskinesia with just short-term usage of this drug. This side effect might develop via an intact nigrostriatal pathway connecting the substantia nigra pars compacta with the dorsal striatum involved in modulation of the extrapyramidal system. To avoid dyskinesia, bromocriptine dosage and treatment duration should be minimized.

\section{Conclusion}

AM is a known complication in patients with obstructive hydrocephalus experiencing multiple shunt failures, especially aqueductal stenosis. The most accepted mechanism is damage to the monoaminergic projections in the medial forebrain bundle from the midbrain ventral tegmental area to the ventral striatum and prefrontal cortex. First recommended treatment for AM is an endoscopic third ventriculostomy and removal of the previous shunt system. Second recommended treatment is based primarily on bromocriptine administration. To avoid dyskinesia, bromocriptine dosage and duration should be minimized.

\section{References}

1. Rebai RM, Houissa S, Mustapha ME, Azzouni H, Assaggaf S (2012) Akinetic mutism and Parkinsonism after multiple shunt failure: Case report and literature review. J Neurol Surg A Cent Eur Neurosurg 73: 341-346.

2. Kim MS, Rhee JJ, Lee SJ, Kwon SJ, Lee CH (2007) Akinetic mutism responsive to bromocriptine following subdural hematoma evacuation in a patient with hydrocephalus. Neurol Med Chir 47: 419-423.

3. Berger L, Gauthier S, Leblanc R (1985) Akinetic mutism and Parkinsonism associated with obstructive hydrocephalus. Can J Neurol Sci 12: 255-258.

4. Watahiki Y, Narita S, Kurahashi K, Tanaka T, Matsunaga M (1987) Akinetic mutism from recurrent hydrocephalus: Successful treatment with levodopa, bromocriptine and trihexyphenidyl. No To Shinkei 39: 977-982.

5. Anderson B (1992) Relief of Akinetic mutism from obstructive hydrocephalus using bromocriptine and ephedrine. Case report. J Neurosurg 76: 152-155.

6. Moser A, Freyberger HJ, Bruckmann H, Kompf D (1995) Akinetic mutism in decompensated triventricular hydrocephalus. Fortschr Neurol Psychiatr 63: 248-251.

7. Lin KL, Wang HS, Chou ML, Rui TN (1997) Role of cavum septum pellucidum in Akinetic mutism of hydrocephalic children. Pediatr Neurol 16: 156-159.

8. Aidi S, Elalaoui-Faris M, Benabdeljlil M, Benomar A, Chaoui M, et al. (2000) Akinetic mutism and progressive supranuclear palsy-like syndrome after the shunt of an obstructive hydrocephalus. Successful treatment with bromocriptine: 2 cases. Rev Neurol 156: 380-383.

9. Psarros T, Zouros A, Coimbra C (2003) Bromocriptine-responsive Akinetic mutism following endoscopy for ventricular neurocysticercosis. Case report and review of the literature. J Neurosurg 99: 397-401.

10. Lee KS, Kwon OY, Lee L, Park KJ, Choi NC, et al. (2002) A case of Akinetic mutism caused by volume change of cerebral ventricles. J Korean Neurol Assoc 20: 414-417.

11. Tokunaga H, Shigeto H, Inamura T, Kawajiri M, Nakasaki K, et al. (2003) A case of severe parkinsonism induced by failure of ventriculo-peritoneal shunt for aqueductal stenosis. Rinsho Shinkeigaku 43: 427-430.

12. Combarros O, Infante J, Berciano J (2000) Akinetic mutism from frontal lobe damage responding to levodopa. J Neurol 247: 568-569. 